\title{
Leading with Blindfolds? An Exploration of ESL Teachers' Awareness of Semantic Differences
}

\section{Blasius Agha-ah Chiatoh ${ }^{1} \&$ Jude Kaki Chia ${ }^{1 *}$}

\section{* Correspondence: \\ chiajude32@yahoo.com \\ 1. Department of Linguistics, University \\ of Buea, Cameroon}

Received: 10 October 2020

Revision: 23 December 2020

Accepted: 17 February 2021

Published online: 20 June 2021

\begin{abstract}
Teachers of English to Speakers of Other Languages (TESOL) assume different roles amongst which is leadership. To lead effectively, they need to possess some significant awareness of the language in order to adequately respond to learners' needs. One domain of awareness is the ability to distinguish between structurally similar, yet semantically different structures. This study set out to assess ESL teachers' level of semantic awareness in view of establishing their readiness to meet learners' needs within their Zone of Proximal Development (ZPD). The Follow-up Explanatory Research Design was used. Data on the cognitions of ESL teachers were elicited from a questionnaire survey while a test was used to quantify ESL teachers' language awareness levels in the domain of semantics. The quantitative data from the test were analyzed using frequencies and simple percentages while the qualitative data were analyzed using the framework of Content Analyses. The findings reveal that ESL teachers overestimate their knowledge base in components that have a bearing on semantics awareness. However, a majority of them do not wield beyond a fundamental level of awareness as concerns applying that knowledge to differentiate the meanings of structurally similar pairs of sentences. It is therefore crucial for English language pre-service and inservice teacher training to seek ways of enhancing the professional knowledge base of ESL teachers especially in domains that are critical to establishing differences between pairs of sentences that tend to be similar.
\end{abstract}

Keywords: semantics, teacher language awareness, scaffolding, zone of proximal development, interlingual development, feedback 


\section{Introduction}

The ultimate goal of learning a language is to use it for communication. Communication will be unsuccessful or at least incomplete if comprehension is not achieved between/amongst the parties in any communicative event/situation. One area where users of language may experience difficulties with comprehension is distinguishing sentences that may have structural similarities but differ in the meanings they convey. The difference could issue from the choices of some words, tenses, prepositions, or adjectives used in sentences in ways that cause the sentences to become nuanced to the extent where distinguishing between them could hamper teachers' ability to lead in the learning process. Some activities in ESL manuals often test learners' ability to figure out the semantic differences in these kinds of sentences. The ability to effectively distinguish the meaning differences encoded in such pairs of sentences would mark an improvement in the learner's interlingual development which is part of the goal of English as a Second Language (ESL) teaching around the world (Andrews, 2007).

Generally, learners of ESL come into the learning situation with a host of goals, expectations, and challenges (Songhori, 2008). In part, they depend on the teacher of ESL to achieve their goals, meet their expectations, and overcome their challenges. This means that the teacher of ESL needs to be equipped, and at the right level, with the requisite knowledge, skills, and techniques that learners need to support their learning. The provision of this support is what has been termed scaffolding. The term describes the support provided by an expert or adult to a child or novice in one-on-one tutorial interactions in playful contexts (Wood et al., 1976).

\section{Review of the Literature}

Semantic awareness is an aspect of teacher language awareness, the core component of which is subject matter knowledge. Studies on teacher language awareness are therefore useful for review in this study. Research on L2 teacher education is unequivocal about the importance of subject matter knowledge (Rollnick \& Mavhunga, 2016). This knowledge is important for both learners and teachers of English language. Richards (2011) identified what he considers to be the various competences of language teachers as they engage in the process of teaching. The fundamental question, to which he seeks to provide a conceptual response, is how much language is needed by the teacher of language to be able to teach it effectively. This is based on the understanding that there exists a threshold level of mastery of the language by the teacher, below which they will not be able to effectively engage in teaching.

Fontem (2012) pays close attention to the pedagogic beliefs, ineptitudes, training, and subject awareness of teachers of ESL in Cameroon. His work points to pedagogic problems responsible for the problem of English Language Teaching (ELT) in Cameroon such as subject awareness by teachers, adaptability of teaching approaches to learning contexts, and internal organisational problems. Highlighting the importance of teaching grammar and vocabulary, he argues that though most teachers are expected to master English grammar and vocabulary exceptionally well to be able to teach it, this has not been the case. To him, most teachers in Cameroon who have a degree in English are oriented towards literature, not language or grammar teaching. With respect to the lack of subject matter knowledge on the part of ESL teachers in Cameroon, he notes that 'when one listens to English language teachers speak at times one cannot help wondering how they got into higher teacher training college in the first place.

In the wake of the top-down introduction of the Competency-Based Approach (CBA) to ELT in Cameroon in 2012, it became necessary to assess ESL teachers' subject-knowledge readiness as a prerequisite for the implementation of this pedagogic framework. This concern has been addressed by Chia (2015) who found that ELT requires teachers to equip learners to be communicatively competent in a variety of real-life situations. The study was based on the assumption that for ESL teachers in Cameroon to effectively deliver on the demands of the CBA to ELT, they need to possess some threshold knowledge of the subject matter. The findings revealed that ESL teachers have critical subject awareness needs which impair their ability to effectively implement the CBA to ELT.

Similarly, in her Masters dissertation, Edietah (2016), using a questionnaire survey, a structured interview, and an assessment of the curriculum of three government teacher training programmes, investigated pre-service ESL teachers' level of language awareness and reported an acute deficiency in respondents' levels of language awareness and a resulting feeling of unpreparedness to face the task of ESL instruction. With regard to the curriculum of preservice teachers of ESL, she reports that priority is given to courses on pedagogy at the expense of courses that focus on subject-matter knowledge.

One other study within the Cameroonian context that has investigated the subject-matter knowledge of teachers of ESL is that of Taboh and Lando (2017). In order to describe the proficiency levels of 40 ESL teachers, the authors 
used a questionnaire and an interview. The questionnaire which was open-ended was intended to indirectly obtain a written corpus from which the proficiency of teacher participants in different skills were established. With regard to the interview, teacher respondents were equally asked open questions about the English language teaching classroom. This was intended to get a spoken corpus from which the proficiency levels of the respondents would be reported. The findings from the questionnaire revealed that a majority of the forty respondents had difficulties with writing subskills such as spelling (n.36), punctuation (n.33), capitalisation (n.28), sentence construction (n.27), and agreement (n.5). With respect to the interview, respondents demonstrated worrisome lapses in pronunciation and fluency.

One key component of the teacher language awareness required by teachers is grammatical terminology. In fact, grammatical terminology can be useful in semantically drawing the line between syntactically synonymous structures. The importance of terminology has been investigated by Berry (2014) who found that metalanguage is broader than terminology which is restricted to just the use of terms. Metalanguage generally embodies any language about language and must not include the use of terms such as proper nouns for instance.

With focus on ELT in Cameroon, Njika (2015) has investigated the role that Teacher Metalinguistic Awareness (TMA) or Teacher Language Awareness (TLA) can play in not just the teaching, but learning of ESL in Cameroon. With the aid of a mixed-methods design, data from in/pre-service teachers, and students were collected with the aid of a questionnaire, classroom observations, feedback from teaching practice, and end-of-course results. Specifically, the study examined pre-service English language teachers' grammatical awareness as well as their attitudes towards their knowledge of language structure. The study also relied on pre-service ESL teachers' end-of-course examination results to in/validate their claims about their levels of TMA. In-service teachers were equally made to take the same end-ofcourse examination for the same reasons. Findings pointed to a relative positivity in teachers' attitudes as opposed to their poor knowledge of metalinguistics. As the author notes:

regardless of years of experience in English language teaching, many teachers in the ESL contexts in Cameroon lack knowledge about language ability to recognize metalanguage. Thus, the teaching of grammar lessons is generally less frequent. Error correction is not often accompanied by the provision of grammar rule because most teachers are ignorant or not sure of the correction. (64)

The above studies have highlighted the need for ESL teachers to be linguistically aware. This is because ESL teachers' ability to scaffold learning depends a great deal on their awareness of target language. In this connection, Andrews (2007) coined the term TLA) to describe the knowledge that is wielded by teachers of a target language (L2) that enables them to teach effectively. This definition associates effective teaching to an awareness of language, the level of which could determine the extent to which learners develop interlingually. The term language awareness is also frequently used in English teacher education programmes such as Teaching of English as a Second Official Language (TESOL), in the context of the discussion as to whether or not English language teacher trainees are exposed to sufficient LA to cope not only in their practicum but when they undertake teaching full time (Ellis, 2012).

The focus of TLA lies a great deal on an understanding of the grammatical rules that underpin the use of the target language. It is this understanding of grammatical rules/structures that ultimately informs the ability to semantically distinguish between pairs of sentences that seem similar yet differ in meaning. The ability to distinguish between structurally similar yet semantically dissimilar pairs of sentences is crucial to the ESL learning process in that it regulates the gaps of comprehension that may ensue as well as the misinformation that may result from using either half of the sentence in incorrect ways. The importance of TLA has found expression in English teacher training programmes such as The Certificate in English Language Teaching to Adults (CELTA) in which section 2 of 5 is titled 'Language analysis and awareness' (see ETEC, 2015). The goal of this section is to ensure that certified teachers of English have the requisite level of language awareness needed to meet learners' needs in domains that require sensitivity to language structures.

\subsection{Teaching and Leading}

The term leader often features amongst the metaphors used to describe teachers of English to Speakers of Other Languages (ESOL). Asmalı and Çelik (2017), for instance, have reported that EFL teachers with varied experiences use metaphors such as knowledge providers, nurturers, artists, challengers, innovators, learners, and co-operative leaders. The reasons why teachers may see themselves or be classified as leaders vary. For instance, the role of teachers as leaders could find expression in responsibilities such as guides, football coaches, orchestra leaders, prompters, 
facilitators, organizers, and scaffolders. Their inherent nuances notwithstanding, each of these responsibilities highlight the need to cooperate with learners towards meeting learning outcomes.

In recognition of the teacher's role as a group leader, Dreikurs et al. (1999) recommend group discussion as a means by which teachers can build successful learning environments. The nature of the metaphor of teachers as leaders presupposes that they have a goal or objective towards the learner, and this goal or objective can find expression in clearly stated learning outcomes. Teachers' responsibility is therefore to provide the guidance, facilitation, scaffolding, coaching, or prompting needed by learners to meet these outcomes. Though the indicators of effective leadership as far as teaching ESL have not been empirically reported, they can be anticipated. For instance, the extent to which teachers of ESL can provide the leadership needed by learners to meet learning outcomes, is dependable on their level of awareness of the target language. One area in which this awareness can be demonstrated is in the domain of semantic differences between structurally similar sentences or expressions. This implies the testable assumption that leading as teachers of ESL requires, at least in part, an awareness of the target language.

\subsection{The Teaching and Learning of ESL in Cameroon}

English is one of the two official languages enshrined in the constitution of the Republic of Cameroon. Cameroon operates two educational systems - the English and the French systems of education, with English taught in both from pre-nursery school through to the university. It is taught as a second language in the English subsystem of education and as a foreign language within the French subsystem of education. Secondary school learners of English within the English subsystem of education vary in their linguistic profiles. While some already speak either a vernacular or Cameroon Pidgin English (CPE) prior to enrolling in school, others speak both or none (Fontem, 2012).

Irrespective of their linguistic background, the content of the English language syllabus and the teachers trained and deployed to teach English in the English subsystem of education are consistent with the teaching of ESL. Secondary school teachers of ESL in Cameroon vary in their training and qualification. While some with either an Advanced Level certificate or university/graduate degree have undergone professional training in any of the government-run Higher Teacher Training Colleges in Cameroon, others have the same qualifications without professional training. Though both categories of teachers teach in the different types of secondary schools (Government, Confessional and Lay Private), a majority of those with professional training teach in government-run secondary schools while those without training teach in either Confessional or Lay private schools. Despite the difference in terms of professional training, all English language teachers in secondary schools are expected to belong to a Professional guilt known as the Cameroon English Language and Literature Teachers' Association (CAMELLTA). This platform is run by an elected body with executive positions occupied by both teachers without bias to professional training. The principal responsibility of the guilt is capacity building for members in two domains - pedagogical competence and subject matter competence. Within the framework of subject matter competence, this guilt seeks to empower teachers with the subject matter knowledge required to improve teaching and advance learning through the provision of feedback. In the light of the academic backgrounds of ESL teachers in Cameroon, their professional training and their affiliation to a professional guild where they benefit from capacity building in the domain of subject matter, it is expected that their TLA should have been levelled-up to the extent where they can teach effectively.

\subsection{The Problem}

Leadership is one of the responsibilities of Teachers of English to Speakers of Other Languages (McGee et al., 2014). To lead effectively, these teachers need an awareness of the language that enables them to, among other things, semantically distinguish between structurally similar pairs of sentences. As concluded by Andrews (2007), a linguistically-aware teacher of ESL is more capable of availing learning opportunities for students. However, the absence of a systematic account of the semantic awareness of ESL teachers has been observed to impair the effectiveness of many teachers of ESL in Cameroon (Njika, 2015).

\subsection{Research Questions}

This study was guided by the following research questions.

1. What is the semantics awareness level of ESL teachers?

2. How does the semantic awareness level of ESL teachers affect their ability to teach affectively?

\subsection{Objectives of the Study}


Based on the importance of semantic awareness and its potential to endow teachers of ESL with leadership competencies, this study set out to accomplish the following objectives:

1. Describe ESL teachers' level of semantic awareness

2. Account for how semantic awareness deficiencies manifest in teaching circumstances.

\subsection{Research Hypotheses}

This study was based on the following hypotheses.

1. Subjects will not differ in their levels of semantic awareness.

2. The manifestations of semantic awareness deficiencies will not differ by subjects.

\section{Methodology}

\subsection{Participants and Setting}

The participants in this study were sampled using the critical case sampling approach, defined by Patton (2001), as a small number of cases that, can "yield the most information and have the greatest impact on the development of knowledge" (p. 236). Four criteria were established in the current study for the selection of participants viz: They must have a first degree in either English language, linguistics or Literature; have completed a two-year training course in any of the Higher Teacher Training Colleges (HTTTC) in Cameroon; have been teaching ESL for at least five years, uninterrupted, and must have a positive attitude towards the teaching of ESL. In all, 60 ESL teachers were sampled for this study. Of this number, there were 8 male and 52 female teachers. 16 of the participants were below the age of 30, 19 between 31-45, and 25 above 45. In terms of work experience, 28 of the participants had work experience of between 5-10 years, 19 between 11-20, and 13, between 21-30. Meanwhile, 48 of the participants had a Bachelor's degree while 12 had a Master's degree. At the time when this study was conducted, all the teachers sampled in this study taught ESL within the municipality of Buea, which is the administrative headquarters of the Fako Division in the South West region of Cameroon.

This Division according to Orock and Lambi (2014) has a current population of 444,269 inhabitants and a population density of 216 persons per square $\mathrm{km}$. It comprises six administrative units viz: Buea, Limbe I, Limbe II, Limbe III, Tiko, Muyuka, and Idenau. This semi-urban area is characterised by a variety of economic activities, social amenities, and infrastructural development within its six major towns- Muyuka, Buea, Tiko, Mutengene, Limbe, and Idenau. This geographical setting was chosen not only because it was immediately accessible to the research team, but because it is home to the English Language Resource Centre and modern, well-equipped, and accessible libraries. This research context is also endowed with fairly constant, high speed internet connection that can facilitate teachers' access to pedagogical resources online. Finally, this research context equally has a very active chapter of a nation-wide guilt, called Cameroon English Language Teachers Association (CAMELTA) for teachers of ESL. In view of these reasons, it was hoped that pooling subjects from this context would enable us to maximise the quantity and quality of data to be procured, with respect to teachers' level of TLA.

\subsection{Research Design}

The research design used in this study is known as the Follow-up Explanations Design, which is derived from the Sequential Explanatory Approach to mixed methods research. In this design, the researcher collects qualitative data in order to further explain the quantitative data and results as indicated on the flow chart below. 


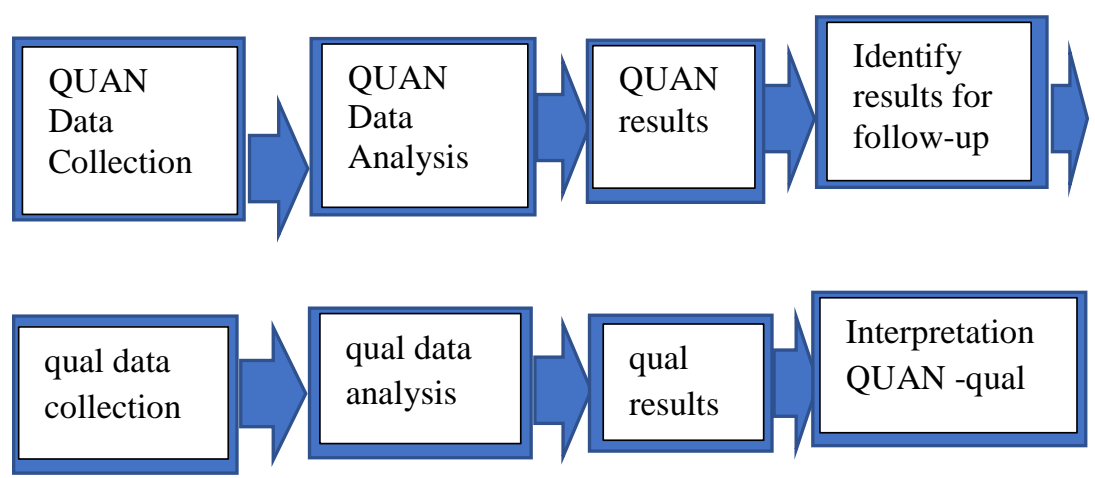

Figure 1: The Follow-up explanatory design (Quan emphasized)

Source: Creswell (2012, p.73)

The justification for the choice of this design stems from the fact this study generates essentially numerical data and employs mostly statistical and computational techniques to measure ESL teachers' level of TLA in the domain of semantics. It was also necessary to elicit nonnumerical data in order to enrich the numerical data. This non-numerical data would help explain how TLA weaknesses in this domain of semantics manifest themselves in instructional situations.

\subsection{Data Collection}

Two instruments were deployed for data collection in this study. These included a questionnaire and a semantics awareness test.

\subsubsection{The Questionnaire}

A questionnaire was used to elicit ESL teachers' views about their perceived levels of TLA in domains that influence language users' ability to distinguish between pairs of sentences that differ in meaning though syntactically similar. These domains include phonology, morphology, lexis, syntax, grammar, grammatical terminology, socio-pragmatic awareness, reading comprehension, communicative language ability, knowledge about learners' level of interlanguage, spelling, and punctuation. The questionnaire used a five-point Likert scale (strongly disagree $=1$, disagree $=2$, neither agree nor disagree $=3$, agree $=4$, strongly agree $=5$ ) in which respondents were expected to state the extent to which they agree that they fully master each of the components listed on the questionnaire.

\subsubsection{The Semantics Awareness Test}

On its part, the semantics awareness test included ten pairs of sentences which was excerpted from Part Four of Paper Two of the English Teaching Competency Test (ETECT). The above test is the intellectual property of the Hellenic American Union Center for Examinations and Certifications in Athens, Greece. Written authorisation was sough and procured prior to administering the test. The participants in this study were tasked to provide explanations of the type they would provide to learners, and in ways that clearly pointed out the semantic boundaries between each sentence pair. Regarding a breakdown of the test items, the ten different pairs of sentences tested different aspects of subject matter as follows: Adverbs/verbs (pair 1), simple present and present continuous tense, (pair 2), lexis, (word choice) (pair 3), polysemy, (pair 4), verb/verb+ adverb (pair 5), polysemy, (pair 6) modal auxiliaries, (pair 7), prepositions, (pair 8), polysemy (pair 9), prepositions (pair 10).

\subsection{Data Analysis}

Regarding qualitative data analysis, each of the responses on questionnaire items were grouped into one of three options to reflect the choices made. These included disagree, neither agree nor disagree (neutral), and agree. The 
responses were computed on an excel spread sheet and the percentages, means, and standard deviations for each of the questionnaire items derived. The data from the questionnaire was used to establish the extent to which ESL teachers perceive their levels of TLA in the domain of semantics.

With respect to quantitative data, the semantics awareness test was graded on 20 as the correct explanation of each sentence half was awarded a point. To facilitate understanding and description, three levels of mastery based on the United States National Institute of Health (NIH) proficiency scales were used. In the test, a score of 0-9 was given the description Fundamental Awareness, 10-16 ranked as Intermediate Awareness and finally, 17-20 was considered Expert Awareness. These scores were multiplied by 5 to obtain the percentages. Meanwhile, the number of incorrect explanations were computed to establish the frequency of faults.

Meanwhile, any feedback provided by the ESL teachers under study was judged against a backdrop of Swan's (1994) design criteria for pedagogic language rules, with priority given to the first three (truth, demarcation, and clarity), owing to their universality. The summary of the rules and their stipulations are as follows:

-Truth: This rule stipulates that any pedagogic rule needs to be true (p. 46)

-Demarcation: This rule requires that any pedagogic rule needs to clearly indicate the limits of the use of any grammatical structure (p. 47)

- Clarity: this rule simply requires that pedagogic rules should be clear enough to be understood (p. 48)

-Simplicity: As the name entails rules need to be simple, though this might infringe on truth (a) and clarity (b) (p. 48)

- Conceptual parsimony: An explanation needs to use the conceptual framework available to the learner. (p. 50)

- Relevance: This criterion stipulates that a rule should aim to answer only the question that needs to be answered and not some other questions.

To gain insights into the manifestations and scale of weaknesses in the test, a Content Analyses of the different responses that were not awarded a point in the test was undertaken. The responses provided by ESL teachers were treated as feedback they would typically provide in a learning situation. The number of wrong explanations were computed and classified under the relevant design criteria for pedagogic language rules flouted.

\section{Findings}

This section presents the quantitative and qualitative findings, in line with the key objectives of this study.

\subsection{Quantitative Findings}

The qualitative findings include what ESL teachers perceive to be their TLA level in the domain of semantics, on the one hand, and what their actual semantics awareness level is on the other hand. Data on ESL teachers' perception of their level of TLA in the domain of semantics were elicited through a close-ended questionnaire. After keying in teachers' responses and analysing their frequencies it was realised that most ESL teachers under study claim to have expert levels of TLA in the domain of semantics as presented in table 1 below. 
Table 1. Distribution of respondents according to perceived level of TLA

\begin{tabular}{|c|c|c|c|c|c|c|c|c|}
\hline \multirow[t]{2}{*}{ Perceived level of awareness of TLA } & \multicolumn{2}{|c|}{ Agreed } & \multicolumn{2}{|c|}{ Disagreed } & \multicolumn{2}{|c|}{ Neutral } & \multirow{2}{*}{$\begin{array}{c}\text { mean } \\
\mu\end{array}$} & \multirow{2}{*}{$\begin{array}{c}\text { S. dev } \\
\sigma\end{array}$} \\
\hline & $\mathrm{n}$ & $\%$ & $\mathrm{n}$ & $\%$ & $\mathrm{n}$ & $\%$ & & \\
\hline $\begin{array}{l}\text { Phonological awareness (knowledge of pronunciation, } \\
\text { stress) }\end{array}$ & 52 & 86.7 & 01 & 01.7 & 07 & 11.7 & 4.33 & 0.75 \\
\hline $\begin{array}{l}\text { Morphological awareness (knowledge of word formation } \\
\text { processes and how they affect meaning) }\end{array}$ & 56 & 93.3 & 00 & 00.0 & 04 & 06.7 & 4.35 & 0.61 \\
\hline $\begin{array}{l}\text { Lexis (knowledge of synonyms, antonyms, collocations, } \\
\text { idioms, meaning in context) }\end{array}$ & 54 & 90.0 & 00 & 00.0 & 06 & 10.0 & 4.33 & 0.66 \\
\hline Grammar & 52 & 86.7 & 00 & 00.0 & 08 & 13.3 & 4.33 & 0.71 \\
\hline $\begin{array}{l}\text { Metalinguistic awareness (knowledge of grammatical } \\
\text { terminology) }\end{array}$ & 47 & 78.3 & 01 & 01.7 & 12 & 20.0 & 3.98 & 0.70 \\
\hline $\begin{array}{l}\text { Socio-pragmatic awareness (understanding of how society } \\
\text { and linguistic context affect the meanings of some } \\
\text { expressions) }\end{array}$ & 58 & 96.6 & 01 & 01.7 & 01 & 01.7 & 4.03 & 0.86 \\
\hline Reading comprehension & 52 & 86.7 & 01 & 01.7 & 07 & 11.6 & 4.25 & 0.73 \\
\hline $\begin{array}{l}\text { Communicative language ability (the ability to skilfully } \\
\text { communicate your knowledge of subject matter) }\end{array}$ & 56 & 93.3 & 00 & 00.0 & 04 & 06.7 & 4.38 & 0.61 \\
\hline $\begin{array}{l}\text { Knowledge of learners 'interlanguage (knowing learners' } \\
\text { current strengths, weaknesses and developmental level in the } \\
\text { target language) }\end{array}$ & 52 & 86.7 & 04 & 06.7 & 04 & 06.7 & 4.23 & 0.85 \\
\hline Spelling & 58 & 96.7 & 00 & 00.0 & 02 & 03.3 & 4.40 & 0.56 \\
\hline Punctuation & 52 & 86.7 & 00 & 00.0 & 08 & 13.3 & 4.22 & 0.67 \\
\hline MRS & 589 & 89.2 & 8 & 1.2 & 63 & 9.5 & 4.26 & 0.70 \\
\hline
\end{tabular}

The findings in table 1 above reveal that a majority of the respondents $52(86.7 \%)$ agreed that they mastered phonological skills (knowledge of pronunciation, stress) while just 1 (1.7) disagreed and 7 (11.7\%) were neutral. The mean and standard deviation $((\mu=4.33, \sigma=0.75)$ indicate that the bulk of respondents strongly agreed that they have phonological awareness skills. Also, a great proportion of the respondents $56(93.3 \%)$ agreed that they have morphological awareness (knowledge of word formation process and how they affect meaning) while none disagreed and $4(06.7 \%)$ were neutral. The mean and standard deviation $(\mu=4.35, \sigma=0.61)$ reveal that a majority of the respondents strongly agreed that they have morphological awareness. Equally a huge majority of the respondents 54 $(90.0 \%)$ agreed that they have awareness of lexis (knowledge of synonyms, antonyms, collocations, idioms, and meaning in context) while none disagreed and $6(10 \%)$ were neutral. The mean and standard deviation $(\mu=4.33, \sigma=$ 0.66 ) reveal that a majority of the respondents firmly admitted that they have awareness of lexis. Similarly, a majority of the respondents $52(86.7 \%)$ agreed that they have mastery of grammar and while none disagreed, $8(13.3 \%)$ respondents were neutral. The mean and standard deviation $(\mu=4.33, \sigma=0.71)$ show that most of the respondents strongly agreed that they mastered grammar skills. Moreover, a majority of the respondents $47(78.3 \%)$ agreed that they have metalinguistic awareness (knowledge of grammatical terminology) while just $1(01.7 \%)$ respondent disagreed and $12(20.0 \%)$ were neutral. The mean and standard deviation $(\mu=3.98, \sigma=0.70)$ reveal that a majority of the respondents agreed that they possess metalinguistic awareness skills.

Likewise, most respondents 58 (96.6\%) agreed that they have socio-pragmatic awareness (an understanding of how society and linguistic context affect the meanings of some expressions) while $1(01.7 \%)$ disagreed and $1(01.7 \%)$ were 
neutral. The mean and standard deviation $(\mu=4.03, \sigma=0.86)$ show that most respondents agreed to possessing sociopragmatic awareness skills. Equally a lot of the respondents $52(86.7 \%)$ agreed that they master reading comprehension skills while $1(01.7 \%)$ respondent disagreed and $7(11.6 \%)$ were neutral. The mean and standard deviation $(\mu=4.25, \sigma=0.73)$ show that a majority of the respondents agreed that they master reading comprehension skills. In addition, a large chunk of the respondents $56(93.3 \%)$ agreed that they have communicative language ability (the ability to skilfully communicate knowledge of subject matter) skills while no respondent disagreed and $4(06.7 \%)$ were neutral. The mean and standard deviation $(\mu=4.38, \sigma=0.73)$ show that most respondents strongly agreed that they master communicative language ability skills. Similarly, a huge proportion of the respondents $52(86.7 \%)$ claimed that they have knowledge of learners' interlanguage skills (knowledge of learners' current strengths, weaknesses, and developmental level in the target language) while $4(06.7 \%)$ respondents disagreed and $4(06.7 \%)$ were neutral. The mean and standard deviation $(\mu=4.23, \sigma=0.85)$ further shows that most of the respondents strongly agreed that they have knowledge of learners' interlanguage skills.

Also, numerous respondents $58(96.7 \%)$ agreed claimed to have mastered spelling skills while none disagreed and just $2(03.3 \%)$ respondents were neutral. The mean and standard deviation $(\mu=4.40, \sigma=0.56)$ also show that a majority of the respondents strongly agreed to having mastered spelling skills. In the same light a large portion of the respondents $52(86.7 \%)$ admitted that they have mastered punctuation skills while none disagreed and 8 (13.3\%) respondents were neutral. The mean and standard deviation $(\mu=4.22, \sigma=0.67)$ also show that most of the respondents strongly agreed to having mastered punctuation skills. The multiple responses set indicates that most of the respondents $589(89.7 \%)$ perceive themselves as having expert awareness in the different components of TLA identified on the questionnaire. The average mean and standard deviation $(\mu=4.26, \sigma=0.70)$ indicate a high level of teachers' language awareness skills, based on the responses provided. This shows that teachers of ESL in Cameroon have expert levels of TLA in the domain of semantics. Thus, within the Deficiency Needs Analysis Frame adapted for analysis in this study, the TLA needs expressed, by way of self-rating, are negligible.

To further determine the level of mastery of TLA skills, an association between background indicators and perceived level of TLA was established as presented below.

Table 2. Association between background indicators and perception of TLA skills

\begin{tabular}{lllllll}
\hline $\begin{array}{l}\text { Background } \\
\text { indicators }\end{array}$ & Categories & Agreed & Neutral & Disagreed & $\mathrm{N}$ & Chi square test \\
\hline Sex & Male & $79(89.7 \%)$ & 08 & $01(01.1 \%)$ & 88 & \\
& & & $(09.1 \%)$ & & & $\chi 2=0.03$ \\
& Female & 498 & 66 & $08(02.4 \%)$ & 572 & $\mathrm{P}=0.859$ \\
& & $(87.1 \%)$ & $(11.5 \%)$ & & & \\
Age & 155 & 17 & $04(02.3 \%)$ & 176 & \\
& Below 30 years & $(88.1 \%)$ & $(09.7 \%)$ & & & \\
& & 186 & 22 & $01(0.50 \%)$ & 209 & $\chi 2=0.15$ \\
& $31-45$ & $(89.0 \%)$ & $(10.5 \%)$ & & & $\mathrm{P}=0.702$ \\
& & 236 & 35 & $04(01.5 \%)$ & 275 & \\
& 46 and above & $(85.8 \%)$ & $(12.7 \%)$ & & & \\
& & 259 & 43 & $06(01.9 \%)$ & 308 & \\
Work & $(84.1 \%)$ & $(14.0 \%)$ & & & $\chi 2=0.17$ \\
experience & $11-10$ & 199 & 09 & $01(00.5 \%)$ & 209 & $\mathrm{P}=0.602$ \\
& & $(95.3 \%)$ & $(04.3 \%)$ & & & \\
& $21-30$ & 119 & 22 & $02(01.4 \%)$ & 143 &
\end{tabular}




\begin{tabular}{|c|c|c|c|c|c|c|}
\hline \multirow{2}{*}{$\begin{array}{l}\text { Highest } \\
\text { qualification }\end{array}$} & DIPESS II & $\begin{array}{l}459 \\
(86.9 \%)\end{array}$ & $\begin{array}{l}61 \\
(11.6 \%)\end{array}$ & $08(01.5 \%)$ & 528 & $\chi 2=0.25$ \\
\hline & Master's degree & $\begin{array}{l}118(89.4 \\
\%)\end{array}$ & $\begin{array}{l}13 \\
(09.8 \%)\end{array}$ & $01(00.8 \%)$ & 132 & $\mathrm{P}=0.612$ \\
\hline \multirow[t]{5}{*}{$\begin{array}{l}\text { Academic } \\
\text { background }\end{array}$} & English & $\begin{array}{l}218(90.1 \\
\%)\end{array}$ & $\begin{array}{l}22 \\
(09.1 \%)\end{array}$ & $02(00.8 \%)$ & 242 & \multirow{5}{*}{$\begin{array}{l}\chi 2=0.11 \\
\mathrm{P}=0.832\end{array}$} \\
\hline & Linguistics & $54(100 \%)$ & $\begin{array}{l}00 \\
(00.0 \%)\end{array}$ & $00(00.0 \%)$ & 44 & \\
\hline & Literature & $75(85.3 \%)$ & $\begin{array}{l}12 \\
(13.6 \%)\end{array}$ & $01(01.1 \%)$ & 88 & \\
\hline & English/Literature & $\begin{array}{l}230 \\
(83.7 \%)\end{array}$ & $\begin{array}{l}39 \\
(14.2 \%)\end{array}$ & $06(02.4 \%)$ & 275 & \\
\hline & Linguistics/literature & $10(90.9 \%)$ & $\begin{array}{l}01 \\
(09.1 \%)\end{array}$ & $00(00.0 \%)$ & 11 & \\
\hline
\end{tabular}

The findings in table 2 above indicate that the perceived TLA level of respondents as far as semantics is concerned does not depend on sex, age, work experience, highest qualification, or academic background of the respondents. The chi-square tests for the various background indicators at $\mathrm{P}=0.05$ were not significant showing there is no association between the different categories of the background indicators and the TLA of the respondents. This is because of the uniformity in the responses given by the teachers with negligible variations. In fact, almost all respondents agreed in the various categories that they possess high levels of TLA in the domain of semantics. Given that L2 teacher cognitions have been reported to not always correspond with reality (Borg, 2009), it was vital to consider using a test to size up ESL teachers' actual levels of TLA in the domain of semantics.

4.1.1 ESL Teachers' actual level of TLA in the domain of semantics

The second objective in this study was to quantify ESL teachers' actual levels of TLA in the domain of semantics. The table below presents a summary of the findings in this domain, according to the grading scale adopted.

Table 3. ESL teachers' actual TLA level in the domain of semantic differences

\begin{tabular}{lcccccc}
\hline TLA Component & \multicolumn{3}{c}{ TLA Level } & \\
& Fundamental & & Intermediate \\
& Awareness & & Awareness & & Expert Awareness \\
& $\mathrm{n}$ & $\%$ & $\mathrm{n}$ & $\%$ & $\mathrm{n}$ & $\%$ \\
\hline Semantic differences (SD) & 41 & 68.3 & 12 & 20.0 & 07 & 11.7 \\
\hline
\end{tabular}

This section was graded on twenty. Overall, a majority of the ESL teachers 41 (68.3\%) had just fundamental awareness. Some12 (20.0\%) subjects presented an intermediate level of awareness in semantic differences while 7 (11.7\%) had expert awareness as far as establishing semantic differences between the 10 ten pairs of expressions in this study is concerned. This marks a huge contrast with their claims about their level of TLA in this domain.

\subsection{Qualitative Findings}

The qualitative findings in this study relate to the manifestations of TLA deficiencies in the domain of semantics. This was achieved by content- analysing a sample of all the responses that were not awarded a point because the explanation provided was deemed inadequate or wrong. By analysing the explanations, it was realised that most of the responses analysed did not meet the design criteria for pedagogic language rules such as demarcation, truth, clarity, and 
relevance. Statistically, while criteria such as relevance and truth had very high frequencies, those for clarity and demarcation were low as indicated in the table below. As also evident in the table below, some subjects correctly identified one half (A or B) of the pairs of sentences but could not do same for the other half (A or B), hence the blank spaces on some columns in the table below. This has the potential effect of making it difficult for their learners to resolve comprehension issues that stem from this distinction.

Table 4. Showing the totals per criteria flouted in the semantic differences test

\begin{tabular}{lllllllllc}
\hline Question & N & \multicolumn{2}{c}{ Demarcation } & \multicolumn{2}{c}{ Truth } & \multicolumn{2}{c}{ Clarity } & \multicolumn{2}{c}{ Relevance } \\
\cline { 2 - 10 } & & A & B & A & B & A & B & A & B \\
\hline 1 & 60 & 2 & 9 & 22 & 12 & 1 & & & \\
2 & 60 & 1 & 5 & 1 & 5 & & & 22 & 9 \\
3 & 60 & & & 2 & & & & & \\
4 & 60 & 3 & 2 & 5 & 11 & & & 19 & 8 \\
5 & 60 & 1 & 2 & 11 & 8 & & & 10 & 12 \\
6 & 60 & & & 12 & 17 & & & 5 & 2 \\
7 & 60 & 2 & & 6 & 2 & & & 26 & 25 \\
8 & 60 & 2 & & 3 & 4 & & & 4 & 15 \\
9 & 60 & & & & 8 & & & 3 & \\
10 & 60 & & & 2 & 5 & & & 4 & 3 \\
Frequency & & 11 & 18 & 66 & 72 & 1 & 00 & 93 & 74 \\
Total & & 600 & 600 & 600 & 600 & 600 & 600 & 600 & 600 \\
\hline
\end{tabular}

The totals (600) above were derived by multiplying the number of subjects (60) who took the test, by the number of sub questions (10). The bar chart below ranks the frequency of the criteria flouted in the section, based on the responses provided by the test subjects. The frequencies have been classified in a descending order and according to both halves of each sentence pair. 


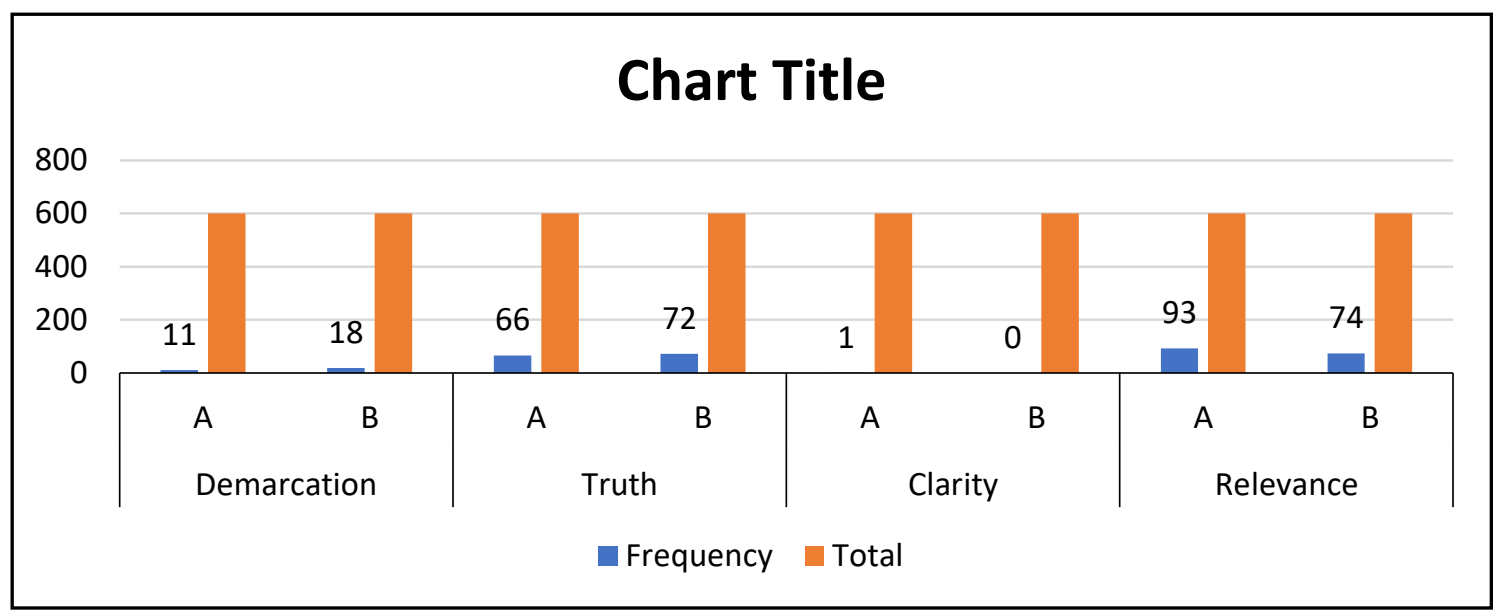

Figure 2. Showing the frequency of criteria flouted in the semantics differences test

\section{Discussion}

The findings in the current study are discussed in line with the research questions posed in this study and available research evidence in this regard. With regard to the first research question pertaining the semantics awareness levels of teachers, it was found that ESL teachers overate their mastery of key aspects of language structure that are critical to their ability to correctly decipher the differences between syntactically similar sentences with differences in meaning. This key finding highlights the relevance and importance of cognition in L2 teaching/learning research. Cognition has been defined by Borg (2009) as what teachers know, think, and believe which cannot be ignored in the course of research in L2 these tend to impact L2 teacher behaviour in the classroom. This is relevant to the current study in that if teachers think of themselves as possessing expert levels of TLA in the domain of semantics when in reality they do not, it could foil the hopes of learners who depend on them, and the goals of teaching.

This is so because teachers cannot offer what they do not have and as Larsen-Freeman (2002) has pointed out, 'teachers teach subject matter the way that they conceptualise it' (p.104). Similarly, Chia (2015), has noted the discrepancy between ESL teachers' awareness of the competency-based approach and language awareness on the one hand, and their ability to effectively apply this approach or use the language effectively in the classroom on the other hand.

The current study also reports that teachers' claims to the knowledge base needed to wield semantic awareness are untenable. Thus, if what ESL teachers consider to be the difference between semantically dissimilar pairs of sentences is unfounded this may be projected unto learners with the potential to impede the language learning process. How teachers perceive grammar and its place in ESL teaching could also inform their level of and interest in the mastery of the rules of grammar. Though the current study does not enlist ESL teachers' views about grammar and grammar teaching, a study of grammar teaching views of pre-service teachers, reveals that the process of teaching grammar is anxiety-inducing and almost half of them experience insecurity teaching grammar because they do not consider themselves authorities in grammar instruction. Implicitly, if teachers of ESL are sceptical or uncertain about their readiness to teach grammar, besides lacking the grammar skills in themselves, they therefore would lack the input needed to effectively distinguish between pairs of structurally similar sentences.

The actual ability of ESL teachers under study to distinguish between semantic pairs of sentences is dismal, as only 7 of them present expert awareness in this regard. This finding highlights the importance of teachers' subject matter knowledge in the language teaching process as highlighted by Fontem (2012). Semantics is a crucial domain where teachers' knowledge is resourceful in the learning/teaching process. It has been noted that teacher knowledge is complex and depends on the context and individual experiences though some aspects are fairly common to some teachers (Verloop et al., 2001).

In the context of the current study, the knowledge-base that is expected to be common to the teachers under study is broad but such that they can effectively figure out the semantic differences between the sentences under study. The knowledge base of ESL teachers has equally been studied with specific attention to aspects such as grammar, 
vocabulary, and terminology. For instance, ESL teachers' lack of subject matter knowledge in the domain of semantics as reported in this study is in sync with a previous study by Taboh and Lando (2017) who found that ESL teachers in Cameroon have difficulties in writing subskills such as spelling, punctuation, capitalisation, sentence construction, and agreement. Though these are considered subskills of writing their influence in accounting for semantic differences is not unfounded. For instance, a change in capitalisation of the initial letter could account for a difference in the meaning of a word like 'august.'

The second objective of this study was to establish how semantic awareness deficiencies manifest in teaching circumstances. The findings reveal that ESL teachers grapple with issues of demarcation, truth, clarity, and relevance when providing feedback to learners. This supports the findings in a survey of the metalinguistic awareness of ESL teachers in Cameroon, by Njika (2015) who found that teachers' correction of errors 'is not often accompanied by the provision of a grammar rule because most teachers are ignorant or not sure of the correction' (64). This lack of grammatical awareness could invariably extend to a weakness on the part of the teacher to semantically distinguish between structurally similar sentences in English. For instance, the manifestations of ESL teachers' LA weaknesses in the domain of semantics (see table 4) gives an idea of the nature and scale of the problem. The lack of demarcation, truth, clarity, and relevance manifested in some of the explanations provided by ESL teachers compromises the quality of feedback, with implications for learning.

According to Hattie and Timperley (2007), the function of feedback usually is to clarify the learner on some issue for which he/she needs help. It is therefore necessary that such feedback aligns with the design criteria for pedagogic language rules. In addition to semantic awareness, ESL teachers need to master content from other disciplines to be able to teach English effectively. In a study of the cross-curricular awareness of ESL teachers in Cameroon, Chia (2020), found that $83.33 \%$ of the teachers surveyed acknowledged that their knowledge of other fields facilitates their teaching of English. However, their awareness of cross curricular content was limited to arts-inclined subjects (acknowledged by between 21-28 out of the 30 subjects surveyed) as only between 5-16 out of the 30 ESL teacher subjects in the study claimed to master content from the sciences. By implication, they would hardly facilitate English language learning when dealing with textbook units that dwell on the sciences.

\section{Conclusion}

One of the ways by which ESL teachers can lead in and promote learning is by being able to deploy the knowledge gained in other levels of linguistic analyses to provide constructive feedback in the domain of semantics. Establishing semantic differences between similar syntactic structures may pose a challenge especially to learners of ESL in a nonnative context such as Cameroon. Meanwhile, an understanding of semantic differences would enable learners to achieve clarity in communication and to effectively deconstruct nuances in texts. Teachers of ESL have to be able to address learners' worries that relate to appropriately assigning meanings to syntactically similar linguistic structures. Teachers' ability in this regard can be determined by the extent to which they master other levels of linguistic analysis. After assessing ESL teachers' ability to differentiate the meanings of structurally similar pairs of sentences, this study has established subjects' TLA levels in the domain of semantics, the nature of difficulties faced, and the implications of the findings for the teaching and learning of ESL in Cameroon.

\subsection{Implications of the Findings}

The current study has implications for the teaching and learning of ESL in Cameroon. Specifically, the study has ramifications for the different actors in the teaching of ESL in Cameroon. First, the dismal TLA level in the domain of semantics in this study signals a deficiency in the professional knowledge base of ESL teachers under study. This is because an understanding of semantics is the function of the subject's subject matter knowledge in lower levels of linguistic analysis such as phonology, morphology, lexicology and syntax. This invariably calls to question, the content of the training received by ESL teachers prior to and in the course of teaching. The fundamental awareness evidenced by in-services ESL teachers in the semantic differences test is consistent with a blindfold that should be lifted if learners must benefit from the knowledge base of the teacher.

Second, the scope of subject matter inadequacies relating to semantic awareness as exhibited by ESL teachers reveals their diminished ability to cope with the expectations of learners. This could account, at least in part, for the poor performance of learners not only in end-of-course examinations such as the Cameroon General Certificate of Education (CGCE) as reported by Fontem (2012). In the light of these findings, policy stakeholders need to consider revamping the curriculum of pre-service and in-service teacher training geared towards meeting the subject matter 
needs of (would-be) teachers of ESL. Finally, it is necessary for policy to consider implementing quality assurance measures that could better prepare teachers of ESL to provide feedback that advances learning. One way to go about this could be for pedagogic inspectors to ensure that ESL teachers teach not only what they feel comfortable with but what their tested ability has proven they can handle. With this, teachers would feel more confident and learners would have better chances of scaling up their interlingual development.

\section{Acknowledgement}

We are grateful to the University group for English Language and Education Research (UGELER) for availing the finances needed to undertake this study. We are equally grateful to the teachers of ESL in the Buea municipality who volunteered to take part in this study.

\section{References}

Andrews, S. J. (2007). Teacher language awareness. Cambridge University Press.

Asmal, M., \& Çelik, H. (2017). EFL teachers' conceptualizations of their roles through metaphor analysis. Journal of Language Linguistic Studies, 13(2), 13. https://www.researchgate.net/publication/320704021_EFL_teachers\%27_conceptualizations_of_their_roles_t hrough_metaphor_analysis

Berry R. (2014) Investigating language awareness: The role of terminology. In: Łyda A., Szcześniak K. (eds) Awareness in action. Second language learning and teaching. Springer, Cham. https://doi.org/10.1007/978-3319-00461-7_2

Borg, S. (2009). Introducing language teacher cognition. https://docplayer.net/21093215-Introducing-languageteacher-cognition.html

Chia, J. K. (2015). Teacher subject awareness in the context of the competency-based approach to English language teaching in Cameroon (Unpublished master's thesis). University of Buea, Cameroon.

Chia, J. (2020). Towards a cross-curricular awareness for ESL teachers in Cameroon. Journal of Linguistics and Foreign Languages, 1(2), 7-18. https://royalliteglobal.com/jlfl/article/view/297

Creswell, J. W. (2012). Educational research: Planning, conducting, and evaluating quantitative and qualitative research (4th ed.). Merrill.

Dreikurs, R., Crunwald, B. B., \& Pepper, F. C. (1999). Maintaining sanity in the classroom: Classroom management techniques (2nd ed.). Taylor and Francis.

Edietah, S. (2016). Pre-service teacher training and proficiency in Cameroon (Unpublished master's thesis). University of Buea, Cameroon

Ellis E. M. (2012). Language awareness and its relevance to TESOL. University of Sydney Papers in TESOL, 7, 1-23. https://pdf4pro.com/view/language-awareness-and-its-relevance-to-tesol-322a2a.html

Fontem, A. N. (2012). Investigating modes of language acquisition and learning. Miraclaire Publishing.

Hattie, J., \& Timperley, H. (2007). The power of feedback. Review of Educational Research, 77(1), 81-112. doi:10.3102/003465430298487

Hellenic American University. (2015). The English teaching competency test. Hellenic American Union. https://www.hau.gr/?i=examinations.en.hellenic-american-university-examinations

Larsen-Freeman, D. (2002). The grammar of choice. In E. Hinkel \& S. Fotos (Eds.), New perspectives on grammar teaching in second language classrooms (pp. 103-18). Lawrence Erlbaum.

McGee, A., Haworth, P., \& MacIntyre, L. (2014). Leadership practices to support teaching and learning for English language learners. TESOL Quarterly, 49(1), 92-114. https://doi.org/10.1002/tesq.162

Njika, J. A. (2015). Teacher metalinguistic awareness as an essential component of language teaching/learning: Case study of ELT in Cameroon. Syllabus Review, 6(2), 23-52. https://www.ens.cm/files/syllabus_lettres/SyllabusVol_6223_52.pdf 
Orock, F. T., \& Lambi, C. M. (2014). Constraints on the cultivation of Colocasia esculenta in Wetland milieux in parts of the South West region of Cameroon. Journal of Agricultural Economics, Extension and Rural Development 1(4), 40-47. http://springjournals.net/jaeerd/springjournals.netjaeerdarticlesfidelis-

Patton, M. Q. (2001). Qualitative research and evaluation methods (2nd ed.). Sage Publications.

Richards J. C. (2011). Exploring teacher competence in language teaching. The Language Teacher, 35(4), 3-7. https://jalt-publications.org/files/pdf-article/plen1.pdf

Rollnick, M., \& Mavhunga, E. (2016). The place of subject matter knowledge in teacher education. In J. Loughran, \& L. Hamilton (Eds.), The international handbook on teacher education (pp. 423-452). Springer.

Songhori, H. M. (2008). Introduction to needs analysis. English for Specific Purposes World, 4(20), 1-25.

Swan, M. (1994). Design criteria for pedagogic language rules. In M. Bygate, A. Tonkyn, \& E. Williams (Eds.), Grammar and the language teacher (pp. 45-55). Prentice Hall.

Taboh, B. A., \& Lando, R. (2017). English in Cameroon: Issues of teacher language proficiency. International Journal of English Language Teaching, 4(1), 20-31. doi: https://doi.org/10.5430/ijelt.v4n1p20

Verloop, N., Driel, J. V., \& Meijer, P. (2001). Teacher knowledge and the knowledge base of teaching. International Journal of Educational Research, 441-461. https://www.academia.edu/14227339/Teacher_knowledge_and_the_knowledge_base_of_teaching

Wood, J., Bruner J. S., \& Ross, G. (1976). The role of tutoring in problem solving. Journal of Child Psychology and Psychiatry, 17(2), 89-100. https://doi.org/10.1111/j.1469-7610.1976.tb00381.x 


\section{APPENDIX 1}

\section{Questionnaire: Semantic Awareness amongst ESL Instructors in Cameroon}

\section{Dear respondent}

This study seeks to explore ESL teachers' awareness of semantic differences in similar linguistic structures. Please, honestly fill out the questionnaire to the best of your ability. This is not an exam so there is no wrong answer. Thanks.

\section{Section A: Demographic Information}

Name (optional)

Age (years) $0-25 \square 25-30 \square 31-45 \square 45-55$

Work experience (Years) $0-5 \square 5-10 \square 11-15 \square 16-20 \square 21+$

Sex: Male $\square$ Female

Highest qualification: A level $\square$ DIPES1 $\square$ BA $\square$ DIPES2 $\square \quad$ MA $\square \quad \operatorname{PhD}$

Academic Background (you can tick more than one): English Language $\square$ Linguistics $\square$ Literature $\square$ Curriculum Studies and Teaching $\square$ Journalism and Communication $\square$ Other $\square$

\section{Section B: Describing Subjects' Perception of Their Levels of TLA}

On a scale of 5 (see scale below), state your perceived level of mastery in the following domains

\section{Scale}

5: Strongly agree (S A)

4: Agree (A)

3: Neither agree nor disagree (NANDA)

2: Disagree (DA)

1: Strongly disagree (SDA)

$\begin{array}{lll}\text { Teacher Language Awareness Indicators } & \text { Scale } \\ & 5 & 421\end{array}$

1. Phonological awareness (knowledge of pronunciation, stress, intonation)

2. Morphological awareness (knowledge of word formation process and how they affect meaning)

3. Lexis (knowledge of synonyms, antonyms, collocations, idioms, meaning in context)

4. Grammar

5. Metalinguistic awareness (knowledge of grammatical terminology)

6. Socio-pragmatic awareness (understanding of how society and linguistic context affect the meanings of some expressions)

7. Reading comprehension 
8. Communicative language ability (the ability to skilfully communicate your knowledge of subject matter)

9. Knowledge of learners' interlanguage (knowing learners' current strengths, weaknesses and developmental level in the target language)

10. Spelling

11. Punctuation 


\section{APPENDIX 2 \\ SEMANTIC DIFFERENCES TEST (20 POINTS)}

In this section, you will read ten pairs of sentences. For each pair, briefly describe the difference in meaning between the two underlined words or phrases. Each item is worth 2 points $(a=1 p t . ; b=1 p t)$.

\section{Example:}

a. Mary likes drinking coffee.

Suggested answer: Mary enjoys drinking coffee.

b. Mary would like a cup of coffee.

Suggested answer: Mary wants a cup of coffee.

1. a. The footballers play hard.

b. The footballers hardly play.

2. a. I saw her eating an apple.

b. I saw her eat an apple.

3. a. The students took their final exams.

b. The students passed their final exams.

4. a. Her husband reminded her to take her pills.

b. Her husband reminded her of her uncle Bill.

5. a. Do you think John likes to come to see me?

b. Do you think John is likely to come to see me?

6. a. My daughter cuts class far too often.

b. My daughter cut class far too often.

7. a. That employee must have been fired.

b. That employee must be fired.

8. a. The children left for school crying.

b. The children left at the school cried. 
9. a. The Red Cross was founded in 1873.

b. The gold cross was found in 1873 .

10. a. Price rises resulted from changes to the economy.

b. Price rises resulted in changes to the economy. 


\section{APPENDIX 3}

\section{SEMANTIC DIFFERENCES TEST ANSWER GUIDE}

1. a. They play rough. OR They make a strong effort.

b. They almost never play.

2. a. She had already started eating an apple when I saw her.

b. I saw the whole action: I saw her eat the whole apple until only the core was left.

3. a. They sat for their exams.

b. They succeeded in their exams.

4. a. Her husband helped her remember.

b. She saw a resemblance between the two. / Her husband looked like her uncle Bill.

5. a. Do you think he enjoys visiting me?

b. Is there a possibility that he may come?

6. a. She makes it a habit of skipping class.

b. She used to skip class in the past.

7. a. It is highly likely that s/he was fired.

b. He/she needs to be fired.

8. a. When they left for school, they were crying.

b. They cried because they were left at school.

9. a. was established

b. was discovered

10. a. The changes led to price increases.

b. The price rises brought about changes. 